\title{
Debating the Autonomy of Reason
}

\author{
D.A. Masolo \\ Department of Philosophy \\ University of Louisville \\ Louisville, Kentucky, U.S.A. \\ damaso01@louisville.edu OR da.masolo@louisville.edu
}

Thought and Practice: A Journal of the Philosophical Association of Kenya (PAK)

New Series, Vol.2 No.1, June 2010, pp.119-148

thoughtandpractice@gmail.com ORthoughtandpractice@uonbi.ac.ke

http://ajol.info/index.php/tp/index

\begin{abstract}
This paper questions the assumption of the bulk of Western philosophy that reasoning in general, and moral reasoning in particular, can be undertaken without any consideration of the unique cultural experiences of those who engage in it. It proposes a communitarian alternative for thinking about subjecthood. It further contends that there is need for professional African philosophers to assist their people in the quest for solutions to current pertinent socio-economic challenges facing them.
\end{abstract}

\section{Introduction: Autonomy of Reason Reconsidered}

The present paper was delivered to the conference on "Philosophy in East Africa: towards Critical Thinking, Professionalism and Democracy", held in Dar Es Salaam, Tanzania, $18^{\text {th }}$ to $20^{\text {th }}$ November, 2009. 
For many years now, UNESCO has been at the center of conferences that reflect on the philosophical underpinnings of culture. And for even longer time is UNESCO's promotion of awareness about, and the development of cultural values around the world. The promotion of the recordings of people's languages and histories, within and across cultures, are well known UNESCO projects. Historians should be acquainted with the authoritative UNESCO General History of Africa. And many philosophers will probably recall the several anthologies across the continent and elsewhere which are results of Unesco-organized conferences. In East Africa particularly, readers will recall the volume, Philosophy and Cultures, co-edited by the late Henry Odera Oruka and myself in 1983. Among the most recent of such efforts was the publication of the proceedings of the Cotonou conference of 2004 under the title La rationalité, une ou plurielle? edited by Paulin J. Hountondji (2007). Not to be ignored are the many other conferences and seminars whose proceedings have yet to be converted into published texts.

A title such as that of Hountondji's anthology mentioned above is significant for several reasons. One of them is that it indicates a leap into a novel terrain - one that escapes the strictures and inertia of the Oxford school of rationality of the 1970s. It does this despite the fact that its title betrays the international and multi-cultural format of many Unescoorganized meetings. Recent shifts in philosophical inquiry have witnessed drifts from fictitious objectivisms and universalisms to how people express differently their motivations or frame their experiences in response to the vast and diverse needs of life across the globe. The point is simple enough - that while it can be assumed that there are many things in the world to which people react and with which they act, what cannot be assumed is what those things are like. What has clearly become important is the interrogation, not of which universal principles will sustain the quest for and help attain one truth for all, but rather what humanly worthy goals, and which motivations, warrant pursuit with the best and most complete rational means for the improvement and sustenance of good living which includes the recognition and respect for the dignity of all humans. ${ }^{1}$

\footnotetext{
1 Please note that I have said, very deliberately, "dignity of all humans" rather than "human dignity" which has been susceptible to a monolithic, essentialist, oppressive, and exclusionist European narrative. By contrast, "the dignity of all humans" gives room for a pluralistic and, therefore, democratic understanding of possible rational choices in the experiences of people.
} 
These new attitudes signal a significant shift from, and are often aimed at the supposition at the center of the so-called "modernity", namely that objectivity was not only a good idea, but that it was indeed possible, its conditions identifiable and definable, and ultimately imposable as the guiding goals of policy in public institutions as well as of moral ideals in private conduct and in personal relations. Those assumptions, crafted elsewhere, became the guiding principles of the idea of "progress", and informed the nineteenth-century ideologies of global power and domination; we became its victims as colonialism and imperialism carried and spread those ideologies abroad from Europe. In the vision of this ideology, there was just one, universal, and commonly attainable terminus ad quem for humanity, and the best power system, built on the unfettered liberties of the individual, could, and had to, make it happen. There was only one problem: that the claimed "humanity" viewed through the values that were identified for and by it, and the political and moral values and orders attached to its possibility, were all European. Of course, objectivity remains always a good idea and ideal that we can meaningfully strive for. But that is all that it is: an ideal that helps and guides us to search for the best in human endeavors, and to sharpen the skills that serve the imagination. The realm of practice, however, does not always lead to concurrence.

Modern European philosophers were notorious for taking to be universal what was actually specific to European cultural changes and adjustments to time, and we now know that only the dominant visions of those adjustments were communicated and spread down the generations as content of preferred and protected values, together with the methodological systems that wrapped them up with justifying theoretical schemes. Thomas Kuhn's work in the theory and historical growth of scientific knowledge exemplifies how contestations within knowledge systems generally sift and retain only the strong aspects that guarantee it survival. ${ }^{2}$ Philosophy is no exception to this

\footnotetext{
${ }^{2}$ Think of the accounts of the suppression of rival findings in the interest of market gains and dominance in the pharmaceutical industry; or think of the now-unmasked suppression of data advising against questionable drilling decisions in the petroleum industry. How many human lives, or how much of environmental tracts and spaces, could have been saved had rival theories had their way in those example cases? The point is that the rival positions were not necessarily scientifically inferior to those that became normative.
} 
evolutionary progression of systems and things through moments of "normalcy" and subsequent subversion. Hegel had seen this dialectic in the human spirit before Darwin said it of organisms. It is important to note here, however, that these observations do not diminish for the human spirit the cultural factor about the specific adaptations, for only what makes its way into accepted or "normal" practice subsequently gets to be communicated to future generations. This is what brings me to the consideration of the obligation that hangs upon us, as members of our societies and institutions with the privilege to attend to our own people's problems by identifying, defining and rationally examining, through insightful discourse, the values that best serve us in our desires to preserve life and to improve its quality for all of us.

\section{Taming our Ever Present Past}

To be sure, like all creative and epoch-changing intellectual traditions, contemporary philosophical thought that advocate certain crucial freedoms for the individual, and by extension advocate a pluralistic world erected on rational principles, arises in recognition of several things. First, it is in recognition of evolved epistemological and moral tenets from those positions of the past that became the bases of oppression of persons whether as individuals or as members of communities and nations. While rejecting the untenable aspects of the past is not always a welcome or comfortable undertaking for all, it is a duty for those upon whom society bestows the privilege of being researchers and thinkers of divers callings. There are discomforting matters in our societies which should cause conceptual and moral pain to any conscientious person whose understanding urges him or her to stop an evil, or one or the other of the calamities of varying proportions in our midst.

How many of you have had the unfortunate opportunity to converse with a person of the village who claims that a witch-doctor, as we have grown to call these con artists, removed a golf-ball-sized animal hairball from under the skin in their belly because they had not been able to go to the bathroom for three days? If we know our biology well, we should know that removing such a large foreign object from under the skin anywhere on the human body would require a pretty large incision that would later require a proportionate number of stitches to patch up. Their story is that witch-doctors do not 
leave marks on their patients, something that I always think should have turned them into some of the most coveted plastic surgeons in this age of bodily manipulations. Be that as it may, the story does not even include an explanation of how the huge lump of hair would have come to be so embedded under the skin in the first place.

Many times narrators of such sad inventions know that you went to school, but either have no clue about what you gain there, or they just do not give regard to what your formal education may have exposed you to, so they expect you to go along. And when you object, chances are that you will be admonished for being "young" and lacking in understanding. In other words, because they do not associate learning with inquiry into the same world you share, it does not occur to them that you could have a different understanding of how the world works. School, and the learning associated with it, is about distant matters that do not - and dare not - separate you from them. This is a narrative version of the long debate that many of you might have detected already as stemming from that controversial school fancily called ethnophilosophy. ${ }^{3}$ But to cut the very long story really short, please consider Hountondji's warning about letting the two orders stand side-by-side. ${ }^{4}$ Here is the danger: while those who are buried in the customary order do not suffer the pain of conceptual confusion even as they die unnecessary deaths, those of us who are acquainted with both and can tell the difference risk all the pitfalls that come with intellectual dishonesty. We face our own challenges, and we ought to pick up the responsibility that they bestow upon us. Unless the media reports we read intentionally mislead us, someone should address at least some of the issues which we notice to emerge around us. Indeed, besides the moral concerns that the examples I have in mind raise, they also are definitely based on skewed biological assumptions that we cannot ignore. Below, then, are some examples.

\footnotetext{
${ }^{3}$ There are positive ways of looking at the term "ethnophilosophy", but I refer here to the now-well known group of scholars whose work, by virtue of it's supposedly philosophical claims and quality, or lack thereof, earned this name from Hountondji, but with a pejorative connotation. That critique is now well known and requires no elaboration here.

${ }^{4}$ See his African Philosophy, Myth and Reality (Second edition), Bloomington, Indiana University Press, 1996, especially the new "Preface". A better defense of his critique of ethnophilosophy can now be found in his The Struggle for Meaning: Reflections on Philosophy, Culture, and Democracy in Africa (English transl. John Conte-Morgan) Athens, OH: Center for International Studies, Ohio University, 2002.
} 
First, we are called upon, collectively and as individual thinkers, to deliberate the deeply worrisome episodes of genocide. On what warranting grounds, and how warranting are those grounds, we should ask, that anyone can or should deserve to die only because he or she lives by a different set of cultural traditions, or because he or she claims to be of a different ethnic group than my own, or because he or she calls his or her deity by that other different name, and worships differently than I do? Or, again, what connections would there be between having red eyes and a bloated belly, or having a discolored skin, and moral guilt? And what if the person bearing such bodily characteristics is even a child? And, finally, even if by reason of some twist in the mind we answered approvingly of the latter few questions, it still remains unclear what kind of punishment is warranted by moral wrongs. I have read stories recently, and seen gory images, of children being killed in some regions of the Democratic Republic of Congo and in parts of the Delta region of Nigeria by their own kin for having red eyes and bloated bellies. To those making the judgements, these conditions were "proof" that the children were witches who deserved death. In highly volatile and unstable conditions such as define the socioeconomic circumstances of the DRC, nutrition is bound to be a problem to everyone, let alone children who become prime victims of war, famine, and other socially ravaging situations. How can well-known signs of malnutrition become signs of moral culpability which we are seen to be happy to meet with the ultimate punishment?

We have been told in widespread media reports that in East Africa, and in Tanzania in particular, persons with albinism are being killed. There is deep concern globally among human rights activists that such persons are being left to die at the hands of town and village mobs or witchdoctors who brand them as "bad omen" to their collective wellbeing, and dismembered body parts of these innocent victims of sheer murder are used for ritual purposes. The general view from a human rights perspective is that the government response is minimal and appears to be limited only to face-saving action when considered against the numbers of victims who have already fallen to these acts of savagery. What appears to be totally absent is the intellectual response when these acts happen on the basis of refutable knowledge claims. So, without amusement, we should ask ourselves: how does one become blame-worthy in any shape or form, let alone being judged to be punishable by death, for how one is born, such as being born with deficiency in the 
amount of melanine required for skin pigmentation? What is the exact content of the knowledge that informs or warrants such extreme actions against our kin and neighbors? In other words, besides the legal ramifications of the lynching of such innocent persons, we also have the moral and biological misconceptions to tackle. While the judicial system will punish wrong-doers, perpetrators of wrongs remain likely to repeat their crimes unless the knowledge that spurs the act is corrected. Being caught may disrupt the timing and perhaps the degree of an act, but it does not necessarily deter its repeat so long as its premises remain intact. Our unavoidable challenge can be framed in the following question form: On who does the responsibility of correcting such misconceptions fall? We may not be directly responsible for these obvious crimes meted undeservedly on our fellow humans, but we are no less culpable when we see and disapprove of them being committed by others yet fail to address them.

Media lenses focused on Africa are not only about the killings. They are also recording Africans' participation in the growing global issue of sexuality, one of contemporary society's biggest challenges to the power and resilience of sheer belief, pitting customary morals against liberal values. The issue of sexuality is not only related to matters of choice of sexual orientation, but also to what it is about biology and sexuality that drive us as societies to be selectively discriminatory, exploitative, and outrightly oppressive of persons of specific genders as we often are when it comes to access to resources and other socially enhancing opportunities. This kind of concern does not, however, dim the importance and equal urgency of the ethical and moral issue at the center of recent shocks to East Africans in regard to revelations of the presence of different sexual orientations and practices in our communities. In that specific regard, a bait has even been thrown directly to philosophers to enter this discussion by the outspokenness of those who are currently charged with helping us identify and discuss possible future directions for legal regulation of our public conduct. With all these issues and concerns to consider as we think about the value and quality of life for all of us, why, I wonder, would anyone ask what it is that is African in African philosophy?

The issues I am talking about do not entail a discussion of a moral crisis in regard to sexuality among ETs. I believe many of you have read about Kenyans making history in 
Great Britain by being the first legally married gay couples there. We don't as philosophers have to preach about these matters in street corners or even in our classrooms, unless our concerns require some activism as part of our demand for better rationally grounded societies. Instead, we can spurr a fruitful and informative debate by asking subtle questions in response to the reactions these news often evoke. ${ }^{5}$ Philosophers are expected to understand some things well, including the risky business of standing up for what is reasonable, right, and just. As Shaaban bin Robert once said, no good or rationally worthy practice can be instituted as a norm in society without deliberation $(\text { mazungumzo })^{6}$. Certainly ahead of his time by many decades, he stood for the rights of women when custom, or even worse, just sheer habit cultivated in colonial economy and social structures, denied our mothers, sisters, spouses, aunts, and grandmothers the sheer dignity of a voice and recognition.

It is our time, the time, for philosophers to rise up because there is no other criterion that would make these issues, and thinking about them, more African than they already are. Focusing on them as our issues will place us on the path to a rational autonomy by reading and discussing everything else with informed skepticism. But we can read, or reread as the case may be, E. E. Evans-Pritchard's Witchcraft, Oracles, and Magic among the Azande (1938). There, we might, for anyone who still thinks that there is need to define what is African about these matters, run into subtle grounds for ruptures in systems of morality across the globe. For me, the primary and most important question we should all ask is: why does anyone need morality? And where do we originate our moral laws from, or, put another way, how do we become aware of which moral principles are rationally better than others, and why?

\footnotetext{
${ }^{5}$ I know that some debates on these matters have been built on concepts and value signifiers that are identified with the Western world, especially the term "liberal". But think of it this way: who does not desire freedom? Or ask if we have considered all aspects of freedom, or which ones are not crucial to a reasonably decent human life that every human being has a right to, and whether freedom of choice of reasonable lifestyle that is harmless to oneself and to others equally free to choose is not one of them.

${ }^{6}$ Shaaban Robert's concerns were with values in their appearance and application toward achievement and sustenance of a social order regulated by virtuous principles as the only way to protect the interests of ordinary people in their daily lives. Hence his idea of deliberation was rendered in the form of mazungumzo or conversations, but there is no doubt that, with appropriate institutional imagination, this idea of mazungumzo would not be extended to academic deliberations. After all, he frequently set the search for the values in dialogical settings reminiscent of the Socratic renditions.
} 


\section{Illusions of Disinterested Reason}

Accounts of our recent crimes across the continent fly in the face of the popular claims, by politicians and scholars alike, that the sacredness of life is the heart of African modes of thought. How do we explain the millions of innocent lives lost in the incessant wars of our post-colonial history? How do we explain the undignifying rituals, such as female child genital mutilation, or the rape of the female child misnamed "marriage", that rob our children of respectable growth and lives? How do we explain our governments' inaction, and the uncaring attitudes of the privileged, in the face of dehumanizing forms of poverty and famine? Many of these situations would not decimate our communities if we treated life with the sacredness that we vainly and insincerely claim it has for us. Or should we ask how suddenly life got to be so secular and worthless? But I believe that sacredness is a metaphor for the high value we bestow on things, and nothing can surpass life in any order of values.

We risk becoming accomplices in evil, unless we can rise up to ask the pertinent questions that will bring a sense of security and equal self-worth to and for all of us. We cannot sit in conferences, or in our campus offices and classrooms, doubting ourselves by asking that someone show us what African philosophy is, or by listening to European tricksters who tell us that we cannot be doing African philosophy unless we speak in our own mother tongues while we surrender intellectual leadership to village quacks. Be weary of such people because they are no worse than the village quacks killing persons with albinism in our midst. The time for these misfits has been long gone, and we can carefully identify genuine and serious collaborators in the cultivation and development of the human good through leveled dialogue. On our part we need to show that our education carries some worth for our societies by addressing the epistemological, moral, and other philosophically significant issues that contemporary beliefs and practices are throwing at us. 


\section{Issues vs. the "How" of Philosophy}

How should we approach the discussion of our problems? My answer is that it does not matter, so long as we adhere to the maxims of thorough understanding and explanation of issues. Again, Shaaban Robert left us excellent examples of such dialogues. More recently, at the University of Dar es Salaam, Ernest Wamba Dia Wamba worked so hard at the idea of visualizing knowledge production as a local process. His quest in this regard was a continuation of what some Tanzanian thinkers had long given leadership in, especially in the well-known knowledge production theories of Mwalimu Julius Nyerere. Our suggestions at solutions will come from our deliberations of whether what is claimed to be the case, in any of the examples I gave above, is really so, and from whether, again given our explanations, the disputed solutions are warranted, or even good at all. I take it that among philosophers, such an approach to issues may lie heavily on conceptual analysis, without making that method, for all that it is worth, an end unto itself.

To be honest, I find the rift between analytic philosophy and any other approach to be a matter that is pretty unnecessary to our goals, and the idea of "philosophy for its own sake" a deeply dishonest intellectual position. But that does not mean that our training as philosophers takes place in departments that act as molds of sorts: it is the nature of the academy. What we should not forget is that schools are some of the most ideologized places one can ever walk into, and our sojourn and molding within these ideological frameworks of the academy are the trademarks they imprint on our minds, and they follow us later to see how we represent them on their behalf. So I want to assume that if you were molded in the corridors where the influence of Frege and his following in the movement of the Nineteen-twenties is predominant, you probably want to call yourself an analytic philosopher. If, on the other hand, you were molded by the hands that got their casting in the Hegelian foundry, you are likely to call yourself a "European continentalist". The latter, and in fact both designations, can be pretty meaningless.

Elsewhere (Masolo 2010, 1-2), I have referred to a collaboration on an article in 1993 between V.Y. Mudimbe and Kwame Anthony Appiah (Mudimbe and Apiyah 1993, 113-138), not only because they themselves discussed the unusefulness of the rift and sometimes irreconcilable animosity between the representatives of these intellectual lineages in the 
European practice of philosophy, but also because it had to take two Africans, outstanding in their own respective rights as magisterial representatives of these two methods - professionally acquired by them in the course of their respective sojourns in the European corridors where they were tools of practice as made available to them as part of the package of their political adoption - to point out that such a rift does not do justice to the need for an integrative approach to knowledge-production. ${ }^{7}$ Their point is that there is more to gain from a collaboration between any set of good methods that help us do what our discipline calls on us to do.

If, therefore, we have learned to do philosophy by asking what it is that justifies certain claims, or makes some better or more obliging than others, then we should pay far less attention to the boundaries of method. Instead, we should adopt and apply them, any of them, together or separately as occasion may require, but as diligently as possible, as they may best serve us in the task of creating the best understanding of the world around us. So, if, for example, I was deliberating the problems I listed above, I would ask, as a way of addressing issues of gender and racial inequity in our midst, what it is that a person's body constitution or skin pigmentation does to his or her capacities in relevant circumstances as to warrant differential treatment in respect to those with similar relevant or required capacities for performing a task. That way we get to address the assumptions upon which various forms of discrimination are built. In more specific relation to the exemplary issues I started with, we would ask what it is about being a victim of malnutrition that deprives a child of his or her fundamental human rights. Even while it remains one of the most controversial forms of punishment of fellow human beings, death is legally administered on others only on the grounds of grave crimes. So, we may ask, what is it about being malnourished, or being deprived — on the strength of our known genetic heredity - of expected skin pigmentation as a result of deficiency in the specific hormone that does the job, that would warrant putting persons suffering those conditions to death? Or how does their condition, which is purely physiological, affect the wellbeing of their neighbors?

\footnotetext{
${ }^{7}$ The methods in themselves may not be "European", but engagement in the warfare between them is what becomes a deep and unnecessary surrogation of a European agendum.
} 
On blaming and murdering our children for being malnourished, the double tragedy faced by these innocents should not escape anyone, as such acts amount to exterminating those who already are victims of socio-economic circumstances brought on by our own failures. The wars over ethnic hegemony, or over control of illicit trade spurred by corruption, are not only senseless and unnecessary, but also create the chain of effects from which malnutrition results. The case of persons with albinism, as I have already indicated, is a genetic condition for which noone bears responsibility in the moral sense of the term. As a result, no victim bears any blame in either case. But how do we get to be aware of the appropriate responses to the specific moral issues related to these examples from a predetermined (a priori) moral principles? Social conflicts, like biological malfunctions due to rogue hormones, are unpredictable in their specifics, much less the kind of concerns they are likely to generate. But if my interest were to take the direction of the location and origin of the moral principles themselves, then, on the basis of what I already know to be suggestions in this matter, I would probably take and compare Immanuel Kant's Metaphysics of Morals, or the Groundwork to the Metaphysics of Morals, on the one hand, and Shaaban Robert's Kusadikika, on the other.

Who, upon reading and contrasting these works, would still say that we have a methodological crisis in philosophy in this continent? I urge that you do not restrain your students from indulging in all the texts available out there, but it will be your duty to point out the virtues of the methods that set them apart, as well as the similarity of the circumstances from which they sprung in the minds of their respective authors. ${ }^{8}$ In doing so, I trust, you will be achieving what Gayatri Chakravorty Spivak, a leading Indian-born postcolonial scholar and theorist, has said recently about how to put the European text to the service of our own quests rather than the other way round (Spivak 1999). For all of us,

\footnotetext{
${ }^{8}$ The backdrop of Kant's work is Martin Luther's protest against Ecclesiastical hegemony in matters of knowledge, morality, and destiny - values which his philosophy bestows on every individual as capable, in autonomy from any institutional hegemony, to arrive at truths as his rational capacity, sometimes mediated by the nature of the object of knowledge itself, allows him. Neither custom nor any type of organized powerhouse has any business shepherding humans to its own perceptions of truths. Shaaban Robert's work, on the other hand, sprang from his reflections on the succession of the powers of domination in Eastern and Central Africa, slavery, and the rise of the economy of native marginalization instituted by these systems with which Islam and Christianity bore only a paradoxical relationship. While preaching moral systems inimical to the core values of the oppressive power systems, the religious institutions lacked the ability to deliver veritable social transformation.
} 
but especially for our young philosophers, whether you are still in school, recently graduated, or just starting on your career, Spivak's critique of European philosophers from a postcolonial standpoint should be embraced as an important lesson, not by adopting everything she says, but by taking up the challenge that we do not read anything without asking crucial questions about where the philosopher speaks from in terms of the particular historical and societal issues that he or she would be speaking from and to. That lesson is old now, yet, at the same time, no lesson loses its salt until everyone it is meant for has heard and learned from it. Do not read or teach Hegel, Kant, Marx, or even John Rawls more recently, as if their claims were rarified universals, whatever those may be. Instead, ask what there is in them that might resonate with your own situation.

\section{Kant and the Disinterested Reason}

The mention of Kant here is instructively deliberate. The liberal movement in our time has made Kant not just a great philosopher, but the greatest philosopher of our time. At least one reason for this rallying around Immanuel Kant's philosophy by today's social and moral theorists of the liberal creed is Kant's view of the nature and role of reason, especially in moral judgements. Although embodied and dependent on the senses in its quest to attain truths about the starry heavens above and the stark objects around us, in moral judgements, he thought, reason is capable of extricating itself from the baggage of distractions which come with the corporeality of the knower. As in our knowledge of the external world of objects, Kant speculated, it was possible to chart out the dimensions of our knowledge of "the moral law within us". In the moral domain, the objective is to determine, or define, that cardinal principle on the basis of which a moral judgement must always be right for everyone by virtue of its rational status alone. There are to be no strings, no attachments on the path to the determination of how we ought to conduct ourselves in respect of right and wrong. The laws herein are almost mechanical, and therefore universal.

The world of moral law, Kant thought, is different, yet it too, according to the German Enlightenment philosopher, must be grounded on some principle(s) which place moral judgements at a comparable if not higher level of universality with those that guide 
empirical experience. In other words, moral judgements, like their counterparts in the judgement of sensory experience, ought to have those grounds upon which they are objectively true for all people at all times. For moral judgements to be so, they must be extricated from idiosyncratic interests of any kind, and their rightness be founded on the laws of moral judgement, namely that they be directly related to what alone must be right - the moral law - and also emerge from the free will that dictates to us that it is not only what we ought to do, but indeed what we must want to do. Thus the only valid ground for a moral act ought to be the product of this law, and such product should be not only right but also the same for everyone in their right mind, and to it they should strive to adhere. Such a law lies in the alliance between reason and (good) will.

The true function of reason, Kant argues, "must be to produce a will which is not merely good as a means to some further end, but is good in itself' (Kant 1981, 9, 396). Thus, for him, doing our duty, following the demands of reason and doing as we ought, doing what alone is right, stands in direct opposition to the directions of desire or what pleases us, and to the demands of our sensuous nature. Consequently, to have moral worth, our actions must be the direct function of our sense of duty with regard to the act. Inclination or habit alone, as customs, including those habits we acquire from memberships of specific faiths, often teach us, is not enough to bestow moral worth on our actions, not even when the inclination is to do what is our duty. Only the motive of duty bestows moral worth on an action. Moral worth has no specific object; rather, it depends, according to Kant, "merely on the principle of volition according to which, without regard to any objects of the faculty of desire, the action has been done" (Kant 1981, 13, 400). It is not the purpose or goal of the action, but the principle or maxim on the basis of which the action is performed, that bestows moral worth on an action. This, in short, is what I understand to be, or call, Kant's idea of autonomy of moral reason.

It is evident that Kant does not suggest that the world is normatively mute, and therefore moral norms depend on us. He is clearly and strongly opposed to such an idea. Even as Kant seems to argue that the idea of moral worth of actions derives from humans alone, such an idea of "derivation" is only in as far as understanding the role of reason in an intuitive manner goes. Hair-splitters, such as Charles Larmore (2004; 2008), for example, are opposed to Kant, as they are to the framework of thinking in European modernity in 
general as influenced by the scientific revolution of the time, for mistakenly suggesting that so much depends on human reason. For this school, morality is a realm that is autonomous of human rational experience itself. In other words, it is part of the higher order of the universe. What I think, in very general terms, to be happening with people like Larmore, is the unease with claims, usually found with extremist forms of liberalism in the Western world, especially in its embrace by libertarians, which claim, in their opposition to any form of institutional interference in people's lives, allegiance to Kant for setting the tone in favor of individual reason as the only basis for what should count as good and right. Their targets are usually the state, the Church, and customary traditions. Is there anything left other than the individual that they do not object to?

The Kantian propositions tally with the libertarian standards and ideals that they alone become the basis of our social living. According to the latter, for example, we should support an ordinance that grants rights to a group of minorities against prevailing prejudices, not because we stand to gain from the consequences of such ordinance, but purely on the ground that there is no rational ground in support of a denial. In such a case, the act of supporting the rights of a minority group acquires a moral worth because it is based purely on the principle that individuals and groups should be granted all rationally defined freedoms and rights, so long as they do not pose a threat to similar freedoms and rights of others. A moral person, according to Kant, is he/she who acts according to principle. Thus, he further says, "Rather than act on the basis of the desires of the moment, the person of principle appeals to a general rule or rationally articulated reason in order to ascertain what to do" (Arrington 1998, 266).

Such principle, as we earlier mentioned, must be one that transcends the moment, such as a specific goal or self-interests of the actor. Now, I am sure you can apply these principles to many issues that we face in our communities today. Here are a few examples: When we run for office in our multi-ethnic urban constituencies, we urge voters to make their choices based on no other factor than what they expect from the occupier of the office, who, in their estimation, is likely to meet such expectations. In other words, we argue, sometimes only by implication, that official performance has nothing to do with gender, ethnicity, religion, or such narrow interest identities. But now we might ask whether we 
should not accord the same judgement to persons whose skins do not appear similar to our own, whether by race or, as in the case of persons with albinism, by some other factor that affects the superficial appearance of our bodies, so long as their capacities are not compromised by such conditions. Or why not accord the same rights to social life-styles to persons whose preferences are not identical with our own, so long as they break no laws in their practices? If you think of these matters deeply, you will be reminded to reflect on why we are prone to veer off the course of reason in regard to some specific issues in life. And often we have no good reason other than mere prejudice. And prejudice against someone on the basis of their ethnicity is neither better nor worse than prejudice based on gender, sexual orientation, dietary preferences, or color of skin. If prejudice is wrong, oppose its manifestation in any form.

Our opposition to Kant is for a different reason, and it is nearly the basis for our opposition to the school that Charles Larmore ascribes to. My point is that our rationalization of practical choices should be done with acute awareness of the possible implications that the principles of judgement in one situation may have for our choices in other situations whose similarities to the former may not always be obvious except by analytical thinking, and that we should strive to be consistent where there are sufficient indications of similarities of objects of our judgement or choice. ${ }^{9}$

Here are Kant's propositions about morality properly speaking:

(i) An action must be done from duty in order to have any moral worth. (Inclination to preserve life, for example, may be good, and people do it all the time, but such an action has no moral worth strictly speaking).

(ii) An action done from duty has its moral worth, not in the purpose that is to be attained by it, but in the maxim according to which the action is determined.

(iii) From (i) and (ii) above, it follows that Duty is the necessity of an action done out of respect for the law. I can indeed have an inclination for an object as the effect of my

\footnotetext{
${ }^{9}$ I once had a group of students from a racial minority group who were eager to vote for an ordinance that was aimed at denying certain rights to gay people until I asked them to consider why the grounds for denying gay people those rights, which were not necessarily guaranteed for members of their group, would not be applicable to them too. If any set of goods, "g", can be denied to any group identified by its culture, then there would be no ground to exempt any culturally definable group from being equally denied the same goods.
} 
proposed action; but I can never have respect for such an object, just because it is merely an effect and is not an activity of the will" (Kant 1981, 12, 399-400).

The form of the moral principle, according to these propositions, is simply the reverence for the law as law. It is the obedience of the law that matters and which must be the deciding motive for an action. "Therefore", Kant says, "the pre-eminent good which is called moral can consist in nothing but the representation of the law in itself, and such a representation can admittedly be found only in a rational being insofar as this representation, and not some expected effect, is the determining ground of the will. This good is already present in the person who acts according to this representation, and such good need not be awaited merely from the effect" (Kant 1981, 13-14). Thus, if, as in the often cited example, a moral imperative has the form of a law like "always tell the truth", it would not matter, in Kant's eyes, whether doing so will result in the death or some other type of harm to oneself or someone else.

Whether they are philosophical or only ordinary, principles of morality are norms, rationally determined to guide conduct where it may occur or only imagined to be possible. This includes the norm that one ought to ignore any effects of his or her conduct when considering the best possible principle. Do we not all think like this when considering the best way to determine a course of action that would be fair to all? Suppose, for example, that you were a member of a search committee charged with hiring someone for a position in your department, and it turns out that one of the applicants is a friend and former classmate of your Chair who is not always a very nice person. So you think, as may indeed be likely, that if you hire this person, the Chair will have an ally, which could then bolster his already nasty personal attitudes. But the specific applicant also happens to be one of your top candidates for the position. Do you argue for the exclusion of this applicant on the basis of the possible effects of his/her hiring, or do you keep focus on the right qualities that make him/her a candidate? And what if the candidate was your friend? What you face is the law of fairness in the process. Should his/her possible impact on the department on grounds not relevant to the advertized qualifications matter to how you make your decision? 
The requirement that a moral norm disregard any effects is arrived at by elimination of what does or does not matter or apply to creating an ideal condition for everyone, indeed anyone involved, not by divine-like intuition. In your deliberations, members of your search committee are likely to ask themselves how they themselves would react, if they were this candidate, upon discovering that they were hired, or shunned, on account of the perception of their possible effect on the department rather than on their relevant qualifications. So they try to assess the moral status of such a decision from their imagined candidature. It is helpful to try to see the other person through one's own judgement of the same circumstance by imaginarily being them. But, as you can tell already, Kant had no room for the "golden rule" - Do unto others as you would have others do unto you - because it requires exactly the opposite of the dictates of the dry duty theory. But the golden rule is often the way most people arrive at the framing of the idealized or "the absolutely objective" rule, whatever that may be. But now imagine that one of your candidates is a member of a minority group who historically have not had equal opportunity for hire at college level. He or she is a good candidate, but not the top one, and there are no other mitigating factors than their qualifications. Your job advertisement particularly encouraged members of underrepresented groups to apply. How, in your view, should your search committee decide on the hire in light of the rule of fairness?

Paradoxically, the idea of "absolutely objective" norms is the insight of transcendental philosophizing, but also its deepest pitfall, especially in practical matters such as morality and politics. By extricating moral knowledge from how people feel about the world and experience, Kant's theory led to and became the reference for moral realism. His own position appears to have been built on the metaphysical component of moral realism, but later philosophers have contributed the semantic and epistemological components. Together, loosely described, they combine to make the claim that there are moral facts, complete with properties, that exist independently of people's beliefs and attitudes about what is right and wrong. In this sense, moral realists claim that moral assertions, which may include assertions of some moral beliefs, can be true or false, and that, with appropriate method, discernment can be made between them.

But, to be sure, opposition to moral realism does not necessarily entail or lead to 
constructivism in the sense that moral judgements are made around interests and therefore lack solid rational grounding beyond what people want or deem useful. Rather, at least the version I deem useful, anti-realism, can be construed as the claim that although morality is an inextricable part of how human lives are lived (because a humane life is essentially human and goes beyond mere survival), moral judgements are of the kind that emerge from the human need to formulate the best regulatory principles for their relations with the objective of creating a humane atmosphere. This being so, the urge for such principles does not arise to an individual in isolation, despite the reflexive character of the process for the rational consideration of which of such principles would be best. There are realities that humans find upon their appearance in the world, and that would be there no matter what else was the case. But there are also other kinds of reality that exist only by virtue of human existence, and hence on or by the strength of the practical sociality that underlies such existence. To abstract from such conditions allows moral realists, as transcendental thinkers, not only to focus on the nature of moral claims or assertions themselves, but, by overlooking human imperfections (such as not being able to know in advance what kind of humanly generated conditions will pertain and the kind of moral concerns they in turn will generate), also to paint a picture of moral ideals that human beings could never fully realize.

It is indeed a long time since Kant wrote the Grounding (or Groundwork) for the Metaphysics of Morals. Therefore his theoretical forecast as well as what he believed to be the strength of the concepts he used may very well be different from our own. Consequently, our reading of this work may involve attributing to it different matters of importance as well as matters with different importance due to the kind of cases that concern us in our own time. Thus our discursive engagement with it today stems from its possible effect on someone who observes in our own time competing commentaries on cases which indicate the impact of socio-historical variations on specific cultures.

\section{African Traditions and the Place of Reason}

Kant's notion that the moral law is present only in rational beings allows us to examine some recent discourses on African traditions with reference to the grounds - whether 
explicitly expressed or only implied - on which they should or should not be respected. The key Kantian concept which links his view with that of liberals in the critique of tradition is the role of reason. The primary role of reason, we have learned, is not to serve limited objects of desire or interest, but to formulate those principles of action which have the character of law - meaning, then, that such principles must have the formal characteristics of law, namely universality and necessity. Universality, we know from the long history of philosophical deliberations on the idea, is the hallmark of reason, whose use, in turn, becomes the hallmark of justice and liberty. A truly universal principle, then, is one which tells everyone how always to act. Tradition, on the other hand, is limited in its application, and addresses matters of specific interests. And as set practices of tradition, customs tell us that some things are done in certain ways by members of certain groups, and not that they must always be so done by everyone. So we leave everyone to do as it may seem best to their customary judgement. Tradition, then, appears to be in sharp contrast not only to Kant's grounding for moral principles, but also to the mission of reason itself.

Yet, to be sure, traditions are hardly formulated just so people can do something for the sake of it, nor just because groups may be different one from another. They are not absurd. What is absurd is the attitude of holding them to be sacrosanct and unadjustable to changing and better values and needs. The factual lack of dialogue within and about traditions cannot be taken as evidence of traditions' relativism, or of traditions' denial of individual freedoms. Kant's grounding of the moral law in the dictates of reason understood in its metaphysical and transcendental abstraction from the social realities of its uses appears, in one interpretation, to be remarkably and unrealistically individualist. For him it is reason, and reason alone by virtue of its inherent ends, that reveals the universality and necessity required of a moral law. Hence, for one to be required to act on any maxim, such maxim must have, or must be shown to be capable of having, the form of universality and necessity as to be requireable of any person as a necessary basis of action.

What one might find paradoxical about those who embrace this position is the account, if any, of their embrace of it. In other words, is it embraced for its value of being capable of enhancing those conditions viewed to be favorable to the enjoyment of certain values. But 
if so, would these not constitute motives for preferring the applicable principle? And are they not arrived at by way of eliminating potential encumberments to an ideal mode of moral agency? Yet Kant writes:

Therefore, I need no far-reaching acuteness to discern what I have to do in order that my will may be morally good. Inexperienced in the course of the world and incapable of being prepared for all its contingencies, I only ask myself whether I can also will that my maxim should become a universal law. If not, then the maxim must be rejected, not because of any disadvantage accruing to me or even to others, but because it cannot be fitting as a principle in a possible legislation of universal law, and reason exacts from me immediate respect for such legislation (Kant 1981, 15).

But is that not what we are as human beings? We have neither experience of what the world will throw at us nor preparedness for all its contingencies, in their actuality or possibilities. But based on the contingencies we know or may be acquainted with, and on what we can reasonably forecast and conjecture based on these, we can design fairly reasonable maxims of practice, and desire that they, and even strive to make them, apply to all cases all the time. But it is a different matter to think that there are, other than this desire alone, a priori maxims with specific identities. Good is not a specific "thing", so it does not bear any specific characteristics other than the properties we transfer to it from the motivations, attitudes and other inner states of people's minds as discernible from their reaction to specific things and conditions of their worlds.

Libertarians believe, among other things, that there are no specific conditions, other than liberty, to which anyone should be compelled to live or act. They prioritize personal autonomy while supporting all endeavors, public and private, which extend and sustain those conditions under which dignified autonomy becomes the right of everyone. For them, as for Kant, nothing is greater in the liberal litany of values than reason as the pillar of this autonomy. It is both its resource and manifestation. Historically, most of this rests with Protestantism, before it passes through Locke and Kant. While discussing religious toleration, Locke argues that what matters most in worship is between the individual and their God, because religious faith is a matter of private conviction. Such matters, that is, 
the inner convictions of the individual, whether they are religious or moral beliefs, remain decisively beyond the reach of the government or any other entity that claims political or other form of public regulatory authority.

"For the modern liberal", Appiah adds, "objection to regulation of religion argues that the choices I make and the understandings I come to in my own search for religious truth are important in part because I chose them in the course of my own search. ... it is that what it is good for me to do depends, in part, on my reflective appropriation of the beliefs and values by which I guide my life" (Appiah 1998, 2-3). These lines can be traced back to those pages of In My Father's House (Appiah 1992) which narrate the defiant standoff between Appiah and the authority of his matriclan, the abusua. Preferring the retinue of tradition to the personal will of the senior Appiah, and in disregard of the reflective choices and values of the younger Appiahs, the abusua, in the person of the senior Appiah's sister, did as much as it could to claim authority in determining the order of funerary matters for her brother. The social lines of the discord in the narrative are obvious, such as narrated in the text (Appiah 1992, 184).

There must be another way of looking at how good lives are produced. In apparent concordance with Kant's separation of object or content of the moral principle, what he calls its goals or effects, from its form, that is, its universality and necessity, Kwasi Wiredu (1996) makes a distinction between custom and morality proper. In other words, he draws a distinction between the relativity of fact and the objectivity or universality of value. The paradoxicality of human embodiment allows for cultural variations in some specific human beliefs and practices while the fundamental basis of these beliefs, as different from their immediate objects, and which Wiredu considers to be the crucial point about being human, remains universally the same for all the members of the species (see Wiredu 1983; 1995). For him as for Kant, such universality is grounded in the universality of the form - that is, that moral rules, like rules of thought, are attuned to the function of the human species - in which ideal human life incorporates considerations of humaneness rather than mere survival.

Then, just as sharply, Wiredu would switch toward the embrace of Dewey's evolutionary pragmatism, namely that such human condition demands a synthetic rather than an $a$ 
priori approach, or, in other words, openness to how reason becomes applicable to the determination of the best outcomes from specific situations. This is what accounts for Wiredu's agreement with Dewey regarding the latter's foundation of logic in the biological complexity of humans as an instrument for the successful attainment of human communication based on the use of rules of speech and sense-making. He criticizes Hume's denial of any value to induction as inconsistent since Hume appeared to realize, despite his rejection of induction, that it was a crucial principle of how humans deal with matters of fact. On the other hand, he argues that he would agree with Kant's categorical imperative only if an "injection of a dose of compassion into [it] would convert it into a principle of sympathetic impartiality" (Wiredu 1996).

According to Wiredu, it is not hard to see the practical strength of such a principle (of sympathetic impartiality), since "it takes little imagination to foresee that life in any society in which everyone openly avowed the contrary of this principle and acted accordingly inevitably would be 'solitary, poor, nasty, brutish', and probably short" (Wiredu 1996, 29). According to this view, Kant's categorical imperative would thus have made more sense if it had been openly built on this human biological principle which "is a human universal transcending cultures viewed as social forms and customary beliefs and practices. In being common to all human practice of morality, it is a universal of any non-brutish form of human life" (Wiredu 1996, 29). Here, Wiredu builds on what is well-known to be particularly underdeveloped in Kant's enterprise. In other words, despite Kant's stress on the mind's discovery, within itself, of its own unity, that of the world, and the unity of the world and mind in experience, it still seemed as though Kant were moving from this personal experience to suggestions of its supposed universality without adequate ontological grounds transcending the individual psyche. Wiredu attempts to close that gap by suggesting that the unity between the particular and the universal does not reside in the abstract. Rather, it is in the biological unity of the species.

For Wiredu, both cognitive and moral capacities of humans are the function of the organically specific type that humans are. Mind, the seat of cognitive and moral reason, is the function of this specific biological condition whose accomplishment (in the specific order proper to being human) depends on the social basis of being properly human. 
Reason resides in the social nature of humans, not in the unity of individual mind; it springs from and prospers by virtue of the act of communication. In fact, if a person were to be isolated from society and deprived of communication with other humans from birth, he/she would be confined to a "solitary, poor, nasty, and brutish", and probably also very short life.

The source of morality proper, Wiredu (1983) argues, cannot be in the supernatural. It is neither the deities, the ancestors, nor the taboos to which are attributed the non-human powers to exact sanctions on those who have committed aberrations. "Justification of behavior can [therefore] only take the form of relating it to rules. [And] Obviously, the rules cannot be justified by reference to themselves but only by reference to higher order rules, where possible, and in other cases, to considerations more general than any specific rule of conduct" (Wiredu 1983, 7). In other words, justification of moral behavior must be sought in the discourses through and by which meanings and effects of behavior are examined and determined against specific and general motives of people in social settings. They are embedded in cultural practice. Obviously, Wiredu presents a communitarian foundation for the values that people enjoy as humans. Even reason, as the formal and practical capacity by which we organize the means and content of communication, would be mute without the facilitation of the community. In morality, as in the broader political order, what is accepted as the governance of behavior is the function "not of any supposed divine inspiration but rather of whatever intrinsic persuasiveness [members'] ideas may have. .... Now, this adherence to the principle of consensus was a premeditated option. It was based on the belief that ultimately the interests of all members of society are the same, although their immediate perceptions of those interests may be different" (Wiredu 1996, 185).

Imagine, once more, what is referred to in my language as a"jadak-kende" - the monadic individual - for whom there are no boundaries to the extent of needs and wants. He or she does not pair "can do" with "cannot do" in their moral senses, for the simple reason that they would not arise in the absence of a conflictual social situation. Their moral meanings originate in social circumstances in which other people's interests suddenly become a reality to be accorded consideration, especially when they are at variance with one's own interests. A "jadak-kende" is an amoral person. Thus consideration of the "can do" and 
"cannot do" regarding his/her actions will be limited to questions of his/her own abilities to carry out his/her plans, or to whether and why any of his/her plans should take precedence over others. In the minimum, communitarians claim that morality is not innate in the sense of preceding the presence of humans among fellow humans. Even in our remotest imagination, thoughts of morality as being autonomous of human desiring and effecting moral maxims in real situations is possible only as abstraction from known real situations, not in a vacuum.

The idea of a "jadak-kende" (the individual as a windowless monad) can only be allegorical. Chances are that even the purely conjectural idea of an "original state" is made possible only by our ruminations on the real. Morality too is about standards and expectations, however low, high, unusual, or outright weird. The idea of the imaginary "jadak-kende" is that there are some matters of conduct about which we can afford some close-to-absolute liberty in the absence of other people (such as eating my meal while absolutely naked, so long as my door and windows securely keep me from any form of intrusion of the outside world), because the maxims that impose expectations on one's conduct would not apply under those circumstances. So you can experiment being a "jadak-kende" inside your space, whatever and wherever it may be, alone, with your door and windows locked and blinded to the outside world. Now imagine that condition to be the permanent and normative state of human existence. Would you still have norms? About what? To what ends, or to control who?

\section{Conclusion}

Metaphysics has always been a fascinating subject. But it has undergone a radical transformation over the years. Gone are the days when human nature was typically explicated in neglect of the concerns of real people in social and historical realities. Gone are the times when bodily characteristics required to live in society and in time was considered a contingent property of human experience. Admittedly, any theory of the self will be abstract, but it does not have to be a construct of an entity that is out of touch with everyday encounters in which one is either a perpetrator or victim of the use of the mechanisms of socio-political fragmentation. The substantial self, by contrast, as we see 
in one's quest to have a grip of who one is and in one's quest to have a grip of what the world around one is and how to deal with it, is an entity that is constantly in a struggle to self-constitute in a sea of processes laid down by other selves in similar struggles, and by institutions that impose norms by and on the basis of which these struggles are carried out. In these processes, the self is either a violator or a victim of others' violations.

One's intersubjective condition allows one to be both an individual and a dependent member of a social world defined by an exchange between its inhabitants. Maybe the abstract self can construct a sense of moral propriety without thinking of his/her own fate as someone whose arms, or those of his/her child or neighbor, have been severed off by someone who thinks that his/her real life is nothing but a mirage, that he/she is only a ghost, or that his/her imaginary absence is not different from dying under the brutality of a machette-wielding attacker. "Conceptualizing the self as an abstract metaphysical entity", writes Fred C. Alford, "leads to a way of thinking that in the end values not the self but the abstract principles from which it is derived" (Alford 1991, 2).

I have tried to propose a communitarian alternative for thinking about subjecthood. Those of my readers who have followed recent discussions in African philosophy will make these connections, and I boldly suggest that this alternative includes the work of Kwame Appiah. Admittedly, there are different strands of communitarianism, and there is some difference between Western and African strands of this ethic. The various strands are however united in their opposition to the familiar individualistic or impersonal conception of the person, or their opposition to a purely libertarian conception of society. Shivji (1986), for example, led a socialist understanding of law that saw it not as an autonomous system of statutes and regulations, but rather as a body of principles whose subject matter is the interests of real people. So when we talk of justice, it is crucial to try to find out what a group of people's moral psychology is about some good. Sometimes people may not exactly be opposed to sharing any said good with other people, but they need to be told, through analytic deliberation, that conflict is engendered primarily by an insufficient understanding of the implications of our actions upon others, or by the conflict between our interests and those of others which we decline to take into serious consideration.

At the 2008 APA (American Philosophical Association) meetings, I was invited to give a 
paper on a panel on "African Communitarianism", and I took a stand for which I have been chided for exhibiting an embrace of the now well-known hybridity theory of identity propounded by Homi Bhabha (1994) as a key element of his post-colonial theory. Failure to articulate my own position more fully and more carefully may have justified such chiding, as I previously may have given too much focus to only one strand of communitarianism, namely the identity communitarianism, especially to the dangers of some of its misunderstandings at the expense of the other and equally important two strands, viz., virtue communitarianism and social-political communitarianism.

By focusing on identity communitarianism, I had intended to dismantle some of the essentialist pitfalls we inherited from Victorian anthropology, and to show the significance of negative moral implications of holding onto particular group identities as if they were part of non-human nature. Several people have similarly argued that essentialist perceptions of identity lie at the root of, and are at least partly responsible for, the hatred and violence against specific groups as we witnessed in the period from World War II until just recently (see e.g. Maalouf 2000; Sen). The reader probably knows someone who was involved in this kind of barbarism as either victim or perpetrator. I argued, against this view of identity, that we are never one thing, if ever we could know what those "things" really are. Unfortunately, we do not know, because, as any little reflection on the migratory history of humanity will show, there is no such identity for anyone. Instead, identities are characterizations we embrace and constantly transform in the course of our lives and engagements with other people equally hybridized like ourselves. Those of us who live and work in environments where group identities are not only problematic in their corresponding relations to value systems of the establishments, but are also a reminder of the ugly pasts, know how sensitive group identity claims can be. They are no more or less political than our own identities have been in service of our complex histories of migrations and settlements many times over.

Identity communitarianism makes the claim that certain strands of liberalism contain a faulty notion of the person because they give insufficient space to particularistic group identities. This strand could be identified with what is now known as "rootless cosmopolitan liberalism", and is espoused by theoreticians who have their national 
political establishments as the only large-scale groups they can identify with, but which they claim to be unnecessary to individual freedoms. These liberals either are, or are cognates of libertarians. By the same token, some identity communitarians fail to notice, and definitely fail to warn, of the lurking dangers of claiming group identities as metaphysical characteristics.

Thus while morally defined identity communitarianism is desirable as a choice to commit to specific cultural modes identified only as roots that one feels proud to identify with and live by as based on positive group values, moral derivations of a metaphysically defined identity communitarianism tends to place those identified as different in socially, morally, and politically disadvantaged relations with oneself. It often results in hierarchized social order that generates conflict such as we have seen across the globe over the past decadeand-a-half or two. To highlight these dangers, I have argued a stationless or hybridized idea of community, not just in post-colonial terms as Bhabha does, but as the driving dynamic in the experiences of real people defined by their multiple roles. Identity communitarianism is about having roots, which we keep and carry with us as we journey across other cultures, but which, nonetheless, are not immutable. Earlier, and in some more recent work, I have drawn attention to virtue communitarianism as well. Because of its recurrence in virtue theory as part of contemporary moral concerns, it is the best known and most widely discussed aspect of communitarianism whose emphasis is the communal rather than the purely individual character of virtue.

Finally, in regard to the third type of communitarianism, namely the social-political one, there could not be a better audience to remind about this than a conference in Dar Es Salaam, Tanzania, albeit recent deviations and allures have tended to distract Tanzanians from it. This is the view that the primary end of a society or polity is to promote, encourage and embody the principle that certain goods ought to be shared equally across such polity, whether it is investment in infrastructural amenities, or the provision of jobs, or the establishment of educational facilities, and other means and modalities for improving the people's well-being, without fear or favour, as a fundamental obligation of the polity as a collective entity. My quest, then, is that our search for philosophical resources be focused on our own societies because we have enough evil to mull over, and enough examples of preceding good thinking to guide us in the direction of defining what 
is or are good for our societies. We cannot be the only place on earth where good is not considered to be sovereign.

\section{References}

Alford, Fred C. 1991. The Self in Social Theory: A Psychoanalytic Account of its Construction in Plato, Hobbes, Locke, Rawls and Rousseau. New Haven: Yale University Press.

Appiah, Kwame Antony. 1998. "The Possibilities of Afro-Liberalism". Unpublished paper presented at the University of Louisville.

Arrington, Robert L. 1998. Western Ethics: An Historical Introduction. Malden, MA: Blackwell Publishers.

Bhabha, Homi. 1994. The Location of Culture. London: Routledge.

Evans-Pritchard, E.E. 1938. Witchcraft, Oracles, and Magic among the Azande. London: Oxford University Press.

Hountondji, Paulin J. 1996. African Philosophy: Myth and Reality, Second Edition. Bloomington: Indiana University Press.

--. 2002. The Struggle for Meaning: Reflections on Philosophy, Culture and Democracy in Africa. Conte-Morgan, John trans. Athens, Oh.: Centre for International Studies, Ohio University.

--. Ed. 2007. La Rationalité, une ou plurielle? Dakar: CODESRIA.

Kant, Immanuel. 1981. Grounding for the Metaphysics of Morals. Ellington, James w. trans. Indianapolis: Hackett Publishing Co., Inc.

Larmore, Charles. 2004. Les Pratiques du Moi. Paris: Presses Universitaires de France.

--. 2008. The Autonomy of Morality. Cambridge: Cambridge University Press.

Maalouf, Amin. 2000. In the Name of Identity. New York: Penguin Books.

Masolo, D.A. 2010. Self and Community in a Changing World. Bloomington: Indiana University Press.

Mudimbe, V.Y. and Kwame Antony Appiah. 1993. "The Impact of African Studies on Philosophy”. In Gates, Robert, V.Y. Mudimbe and Jean O'Barr eds. Africa and the Disciplines: The Contributions of Research in Africa to the Social Sciences and Humanities. Chicago: University of Chicago Press, pp.113-138.

Sen, Amartya. 2006. Identity and Violence: The Illusion of Destiny. New York: W.W. Norton and Co.

Shivji, Issa G. 1986. Law, State and the Working Class in Tanzania. London: James Currey.

Spivak, Gayatri Chakravorty. 1999. A Critique of Post-colonial Reason: Towards a History of the Vanishing Present. Cambridge, MA: Harvard University Press.

Wiredu, Kwasi. 1983. "Morality and Religion in Akan Thought". Oruka, H. Odera and D.A. Masolo eds. Philosophy and Cultures. Nairobi: Bookwise Publishers, pp.613.

--. 1995. "Customs and Morality: A Comparative Analysis of some African and Western Conceptions of Morals". Mosley, Albert G. ed. African Philosophy: Selected 
Readings. Englewood Cliffs: Prentice Hall, pp.389-406.

--. 1996. Cultural Universals and Particulars. Bloomington: Indiana University Press. 